\title{
Los amores de Montaigne Primera escala: Étienne y Michel
}

\author{
Cristina Ambrosini ${ }^{1}$
}

cristinaambrosini@gmail.com

Rec. 12/05/2018, Apr. 19/07/2018

Este escrito es parte de una totalidad más amplia que intenta escrutar la vida, la obra, y sobre todo la época, que le tocó vivir a Michel de Montaigne. Para hacerlo, programamos este viaje en tres escalas, que marcan los amores determinantes del pensamiento de quien puede ser considerado el primer representante filosófico de la Modernidad, antes de la Modernidad misma. En tal caso, si consideramos que es el escepticismo antes que el racionalismo el punto de inicio de la filosofía, será Montaigne antes y como condición de posibilidad de Descartes, quien mostrará la necesidad de retomar los temas ya transitados por la filosofía griega y latina para dar cuenta de su época.

El lapso en el que vivió Michel Eyquem de Montaigne (1533-1592) transcurrió entre dos reinados; el del pusilánime Enrique III, quien fue rey de Francia entre 1574 y 1589, tercer hijo de Catalina de Médicis, y Enrique IV, el primero de los Borbones en gobernar este país. Esta dinastía se prolongará con otros reyes hasta 1830. Enrique IV, el bearnés, será el rey de Francia entre 1589 y 1610, pero, para calmar las intolerancias y las guerras religiosas, concederá convertirse al catolicismo.

El fin de los Valois y el inicio de los Borbones tuvo su inicio el 2 de agosto de 1589 aunque la coronación oficial demorará varios años más. La última guerra de religión termina en 1598 con el edicto de Nantes donde se acuerda la libertad de culto para los protestantes pero ya no estará Montaigne para disfrutar de este logro, tan buscado durante sus intervenciones en los acontecimientos cruentos que desangraron la vida social en su país. Unos años antes, en la noche del 23 al 24 de agosto de 1572 el río Sena se tiñó de rojo por la sangre derramada por los hugonotes y los hechos serán recordados como La Masacre de San Bartolomé. Las matanzas eran moneda corriente y dos puñaladas mortales terminarán también con la vida de Enrique IV en 1610, luego de otros intentos fallidos de regicidio. El Señor de la montaña tiene más de un motivo para, en esos años, preferir la reclusión en La Torre, el lugar de su Castillo, en las afueras de la ciudad de Burdeos, donde ubicó su biblioteca. En otra torre viven sus familiares, sus sirvientes,

1 Dra. Cristina Ambrosini UNLa / UBA. 
el mundo que gobierna su esposa, a distancia suficiente como para que el bullicio de la vida corriente no entre en este lugar consagrado a la lectura y reescritura de la que deberá ser la obra que lo consagre a la literatura universal, los tres libros de los Essais. Estos tres libros, producto de sus vivencias y reflexiones sobre su época serán un aporte decisivo a la filosofía posterior. En definitiva: creemos que tres amores marcaron su obra: el amor a Étienne de La Boétie, el amor a Marie de Gournay y el amor a los viajes. En esta etapa del recorrido nos dedicaremos al vínculo con Etienne de La Boétie, que de los tres es el más reconocido y el que es motivo de múltiples interpretaciones. Prometemos para otra entrega hablar sobre el amor de Montaigne por su hija adoptiva, Marie de Gournay y si aún nos dan las fuerzas y el ánimo, también nos referiremos al amor de Montaigne por los viajes y a las experiencias que obtuvo de ellos.

\section{La amistad testamentaria}

Desde la época de Platón y Aristóteles, el discurso sobre la libertad se escribe sobre la contrafigura de la esclavitud. En el Siglo XVI, en Francia

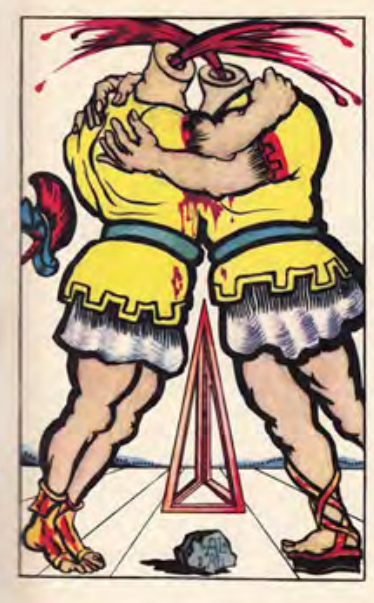
ya no había esclavos al modo griego o romano, o como luego habría en América, pero sí había siervos. La servidumbre indicará una relación degradante en aquellos autores que en esos años recuperan las ideas políticas acerca de un orden político no tiránico, ordenado, al modo del ideal de las polis griegas. Así vemos, en Francia, el fuerte impacto político que tuvo un panfleto de circulación anónima luego conocido bajo el nombre o el pseudónimo de Étienne de La Boétie: El discurso sobre la servidumbre voluntaria. Según la tradición, La Boétie escribe un discurso que luego de su muerte se transformará en un manifiesto inspirador del republicanismo revolucionario, La servidumbre voluntaria, que fue interpretado como un llamado a la rebelión de los campesinos contra la tiranía.

\section{Montaigne, íntimamente} ligado a la vida y la obra de La Boétie, afirma de su amigo, "hubiera preferido nacer en Venecia que en Sarlat, y con razón". Como señala Marilena Chaui (2010. p. 71) para todo el Renacimiento, Venecia, La Serenísima, representa la realización de la República libre, el modelo cívico envidiado por aquellos que vivían bajo la opresión de los monarcas. También es cierto que Montaigne se esfuerza por alejar a su amigo del efecto petardista y tiranicida que provocó la difusión del escrito, cuando fue publicado primero de manera anónima y luego con el título Contra Uno por obra de los calvinistas a partir de 1576 cuando La Boétie ya había muerto en 1563. Según Montaigne este discurso fue un ensayo intelectual juvenil escrito por su amigo a los 18 ańos (en una versión de los Ensayos) o a los 16 (en otra versión). Al

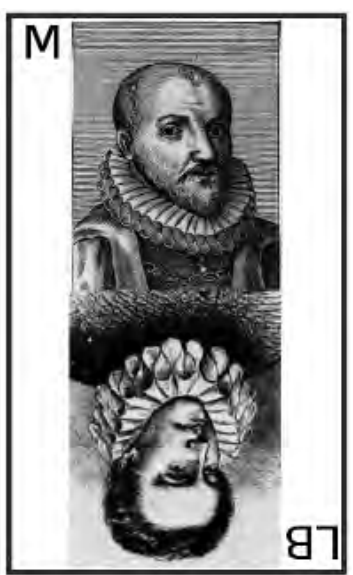


parecer, la intención de apresurar la fecha de escritura es la de "despegar" a su amigo de la Revuelta de la gabelle, en 1548, una revuelta campesina en rebeldía por la imposición de los impuestos a la sal en la zona de la Guyenne que despertó la conciencia de muchos sobre los horrores de las tiranías. El intento de Montaigne es atendible ya que para la época La Boétie, como jurista y parlamentario, había sido encomendado a recorrer varias zonas donde podía haber conatos de rebelión o guerra civil. Recordemos que tanto La Boétie como Montaigne eran personajes destacados dentro del gobierno de Burdeos y por lo tanto súbditos comprometidos políticamente en la obediencia y cumplimiento del orden estatal como súbditos de una monarquía (Chaui, 2010, p. 75). La opinión de algunos historiadores es que el Discurso, fue escrito por La Boétie cuando ya era un profesional formado que ejercía como brillante abogado en Burdeos. Por el nivel de erudición habría sido escrito en 1552 o 1553 (González, 2011, p. 35). De ser así, lo que sí se sabe es que fue leído a la luz de los enfrentamientos con el despotismo de la época, abusos denunciados sobre todo por los hugonotes. Montaigne lo leyó a finales de la década de 1550 y a partir de allí se interesó por conocer a su autor (Bakewell, 2010, p.119).

Para ubicarnos en la biografía de los protagonistas de esta historia, recordamos que Étienne de la Boetie nace el 1 de noviembre de 1530 en Sarlat, en Perignord, una región al sudoeste de Francia, en el seno de una familia influyente donde varios familiares ya habían formado parte del Parlamento. La crianza estuvo a cargo de su tío, el señor de Bouillhonas ya que a temprana edad queda huérfano. Sus biógrafos adjudican a la falta prematura de sus padres el carácter que lo hacía aparecer de mayor edad de la que tenía, al tener que ser prematuramente reflexivo y responsable. Recibe una esmerada educación en el Colegio de Guyena, traduce desde joven textos de Plutarco y Jenofonte. En la Universidad de Orleans, la misma en la que en esos años estudia Calvino, se forma en Derecho y en 1553 ingresa a la carrera judicial. Uno de sus profesores más admirados, Anne du Bourg (1521-1559), concurre al Parlamento de Paris para reclamar y denunciar por los excesos cometidos por los funcionarios de Enrique II en la represión contra los protestantes. El resultado es que termina quemado en la hoguera. Para algunos comentaristas los sucesos que luego desencadenarán este sacrificio serán los que motiven la escritura del Discurso (González, 2011, p.33).

Cuando se conocen con Montaigne, La Boetie ya era un abogado y funcionario del Estado de reconocida trayectoria, se había casado ya con Marguerite de Carle, una viuda que tenía dos hijas de su anterior matrimonio. Una de estas hijas luego se casa con el hermano menor de Montaigne, Thomas de Beauregard con lo que mantienen una alianza familiar aun después de muertos los dos amigos. Montaigne en cambio era soltero, se casó luego de la muerte de su mejor amigo. Los pocos años que pasaron juntos fueron suficientes para solidificar una unión que, hoy en día, podría considerarse como un amor adolescente, tomando en cuenta la retórica encendida de pasión y entusiasmo que imprime el estilo de su vínculo epistolar. A pesar de que la diferencia de edad no era tan grande, La Boétie evidencia experiencia y sensatez mientras que Montaigne es apenas una promesa, un exponente de inteligencia precoz. Por sus escritos, sabemos que ambos se reconocieron en el ideal de la philía aristotélica que valora la identificación con el otro en la virtud. La Boetíe ya era un escritor reconocido y Montaigne apenas había escrito informes legales (Blackwell, 2010, p. 120). La Boetie escribe en un poema sobre Montaigne "Tú estás ligado a mí, Montaigne, por el poder de la naturaleza y por la vir- 
tud, que es el dulce encanto del amor". Señala Backwell que la brevedad del vínculo les ahorró la desilusión (p. 122). En tono irónico se reconocen en las figuras eternas de Sócrates y Alcibíades. El tono ligero, divertido, desenfadado con que se caracterizan podría ser la pista de que en realidad pretenden emular esta amistad espiritual que representa el ideal renacentista de un vínculo puro, despojado de toda connotación tanto sexual como de conveniencia, tal como lo pide Aristóteles. El amor de amistad sería este privilegiado vínculo donde los amigos son "libres", donde no hay dominación, ni interés ni siquiera pesa el exceso fusionante de eros, tal como lo reconocen tanto Aristóteles como Epicuro. El capítulo sobre "La amistad" de los Ensayos da cuenta de las sutilezas de este vínculo singular, único para ambos. Aquí Montaigne, siguiendo las indicaciones de Ética a Nicómaco y casi parafraseando al estagirita, cuando deslinda los poderes de eros de los de la philía admite respecto a esta última:

Si me apuran para que diga por qué lo amaba siento que no se puede expresar sino respondiendo: porque era él y porque era yo. Más allá de mi discurso y de lo que pueda decir de él en particular, hay no sé qué fuerza inexplicable y fatal, mediadora de esta unión. Nos buscábamos antes de habernos visto por lo que habíamos oído uno del otro, cosa que, a diferencia de lo que suele suceder, actuaba más sobre nuestro afecto que el contenido de lo que nos decían, creo que por voluntad del cielo. (Montaigne 2011, p. 178)

Según nos dicen algunos biógrafos, el Discurso, en la época en que se conocieron, circuló discretamente, en pocas copias y no es asombroso que Montaigne se interesara en conocer a su autor. Apareció años después de su muerte como un escrito contra la monarquía francesa. "Era incendiario y tuvo una respuesta incendiara" (Blackwell, 2010, p. 127). El parlamento de Burdeos hizo quemar la segunda edición de la obra "Memorias del estado de Francia bajo Carlos IX" de Simon Goulart (teólogo protestante 1543-1628) que incluía el Discurso, el 7 de mayo de 1579, dos días antes de que Montaigne obtuviese el permiso para publicar los Ensayos. Este solo hecho explicaría el interés de Montaigne por mostrar el republicanismo del Discurso como algo inocuo, un pecado de juventud, y dedicarse solamente a publicar, de la obra póstuma de su amigo, unos sonetos insulsos sobre el amor a las mujeres. Luego decide también eliminarlos en una reedición de los Ensayos. Estas idas y vueltas sobre la publicación de los escritos que le legó su amigo llamaron la atención de los biógrafos de ambos filósofos y acrecientan aun hoy el misterio acerca de quién es el autor del Discurso.

Sabemos que Montaigne sustrajo su publicación en los Ensayos pero defendió las ideas que llevaron a su amigo a escribirlo. Para el estado de cosas que se vivían en Burdeos no deja de ser un acto de valentía. No lo publica pero lo defiende, lo muestra como producto de la efusión juvenil de una mente brillante que denuncia los excesos y propone una especie de resistencia pasiva frente al tirano: no dejarse seducir. Para las interpretaciones de Tolstoi y otros, se interpreta el Discurso como un llamamiento a la no colaboración con el tirano, a rehusarse a servir (Chaui, 2010, p. 76), como una especie de resistencia pasiva al estilo de Gandhi. Todos estos devaneos, estas idas y vueltas sobre la publicación de la obra legada por su propio autor a su amigo levantan sospechas acerca de quién es el autor del Discurso sobre la servidumbre voluntaria. Como dijimos, según los historiadores, sabemos que circularon varias copias antes de que se conocieran perso- 
nalmente y Montaigne leyó una de ellas. Destaca Blackwell que este dato lo conocemos por el propio Montaigne. Quizás fuese el propio Montaigne quien difundió esta versión de los hechos, quien escribió el Discurso e introdujo varios anacronismos como para que el lector atento los descubriera (Blackwell, 2010, p. 131). La idea de que Montaigne escribiera un tratado proto-anarquista y recubriera su génesis de pistas falsas acerca del autor animó las teorías conspirativas que tienen como primer representante la publicación en 1906 de Arthur Antoine Armaingaud al que siguieron en épocas más recientes Daniel Martin, quien considera al Discurso como un crucigrama críptico y David Lewis Schaefer quien se solidariza con la teoría de Armaingaud (Blackwell, 2010, p. 131). De hecho el Discurso aparece siguiendo el mismo estilo de los Ensayos aunque esto podría deberse a la identificación, incluso a las lecturas comunes, de los amigos.

El corto proceso de enfermedad y muerte de La Boetie se conoce a partir de la publicación de una carta que Montaigne escribe a su padre donde cuenta los detalles del deceso. La carta fue escrita en agosto de 1563 y allí cuenta a su padre los detalles de las últimas conversaciones donde su amigo recita en griego y latín a los clásicos y da testimonio de que su decisión fue morir en la fe católica, decisión que imitará Montaigne en el momento de su propia muerte.

En el relato de esta carta consta que el 9 de agosto de 1563, a causa de un agudo dolor de estómago que impidió que La Boetie concurriera a una cena con su amigo, le mandó una carta donde le reclama que acuda a verlo. Montaigne lo hizo y el enfermo le transmite su preocupación por haber contraído la peste que asolaba la zona y a que se contagiara también él. Al día siguiente volvieron a reclamar su presencia junto al enfermo dado que se había agravado el cuadro. Pasó la noche siguiente y ya no dejó el lecho de su amigo. Lo asistió en los preparativos para dejar en orden sus asuntos familiares, "La Boétie estaba muriendo a la manera estoica, lleno de valor y sabiduría racional" (Blackwell, 2010, p. 135). Finalmente, en la mañana del 18 de agosto de 1563 murió La Boetie. Montaigne trasladó a su biblioteca los libros de su amigo para compensar, quizás, su ausencia física con la presencia de sus libros y escritos personales y comenzó a transitar su propio camino como escritor en el tercer piso de la torre donde ubicó allí su refugio.

\section{La Servidumbre voluntaria, el lado oscuro de la libertad}

Si en la historia con Marie de Gournay aparece Montaigne como un seductor, un romántico que abusa de sus talentos para retener a Marie junto a él, como veremos en otro tramo de este viaje, con el debate acerca del destino de la obra que quedó a su cargo aparece otro Montaigne; un intrigante, un doble agente que mientras Enrique III lo pone al frente de la política de entendimiento con los hugonotes, conspira en las sombras para alentar el tiranicidio y dar muerte al Valois.

En una polémica tesis sostenida por Arthur Armaingaud (Burdeos 1842-1935) en Montaigne panphlétaire. L'enigme de contre Un (1910), la hipótesis es que La Boétie no puede ser el autor del panfleto que publicaron los calvinistas, el autor es otro. La audaz teoría es que el autor del Discurso es el mismo autor de los Ensayos, Michel de Montaigne. Bajo los ropajes juveniles de su amigo muerto hace 13 años, Montaigne denuncia la bru- 
talidad de la tiranía luego de la Masacre de San Bartolomé (1572) donde cayeron como víctimas de la intolerancia y de la violencia política muchos de sus amigos y hace circular este panfleto libertario como un arma de guerra.

En la tesis de Armaingaud, Montaigne anuncia en 1570 la existencia del Discurso, en 1572 ocurre la Masacre de San Bartolomé que frustra los esfuerzos por lograr un entendimiento entre católicos y protestantes. Mientras que en los Ensayos se muestra como un Señor prudente, conservador, con declaraciones mesuradas en temas de política y religión, en un pase maestro de prestidigitación se envuelve en los ropajes juveniles de su amigo muerto para lanzar, con prodigiosa habilidad, las ideas emancipatorias y revolucionarias contenidas en el Discurso (Armaingaud, 2010, p.72). Desde 1574, las ambiciones por propiciar la llegada al trono de Francia de Enrique de Navarra, domina el interés de Montaigne y podemos pensar que esta publicación apurará los acontecimientos.

\section{LA SERVITUDE}

VOLONTAIRE, ot

\section{L.E CONTR'UN.}

D ISCOURS

D'ESTIENNE DE LA BOETIE.

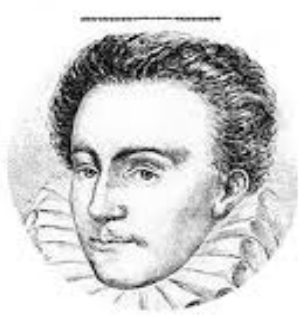

En resumen, según Armaingaud, Michel de Montaigne participó de un plan secreto con los protestantes para destituir a Enrique III, identificado como el tirano, en un escrito que adjudicó a su amigo muerto. Un fragmento de este panfleto contra Enrique III y su corte fue publicado en 1574 en Réveille Matin des Francais (Despertador de los franceses y de sus vecinos) y el texto completo fue publicado en 1577 en las Memoires de l'Estat de France sous Charles Neusfesnie (p.87) que fue mandada a quemar la segunda edición

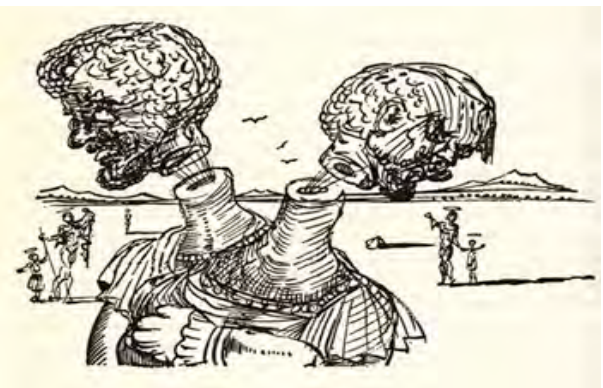
por el Parlamento de Burdeos. La abstención de participar en política no ha sido más que aparente, la reclusión en el castillo para dedicarse a escribir el epitafio de su amigo muerto fue la excusa, detrás de la cual Montaigne justificó la reclusión mientras contribuyó con la difusión de un panfleto petardista e instigador del magnicidio real. Luego de exponer los fundamentos de semejante tesis conspirativa, en Montaigne panfletaire, Armaingaud abre varios capítulos para dedicarse a contestar a los opositores a su teoría ya que, para la época de la difusión de sus ideas, Montaigne está consagrado como una figura icónica de la cultura francesa y los historiadores no se avienen a contradecir con una tesis calumniosa la memoria del padre de su literatura. Las refutaciones a esta tesis atacan sus puntos centrales: el tirano señalado en el Contra Uno no es Enrique III, ubican a distintos personajes anteriores en la Historia a La Boétie, principalmente señalan a Carlos VI (1368 - 1422).También diluyen la tesis acerca de que los mignons nombrados sean los favoritos del último Valois a la vez que cuestionan que sea Montaigne y no otros los que valiéndose del hecho de que el autor del Discurso ya está muerto y no puede ser acusado de sedicioso, utilizan el escrito para desestabilizar el poder gobernante. 
Según esta teoría, el Discurso no es un escrito en contra de la tiranía en general, es un panfleto contra Enrique III y su madre Catalina de Medicis. Según esta hipótesis, en un juego de espejos y de máscaras, Montaigne agrega un panfleto más a los muchos que ya circulaban. El ánimo que aviva el escrito no es puramente teórico, el discurso no alude a cualquier tirano, a un tirano posible y universal. Para Armaingaud el tirano señalado es Enrique III, que asciende al trono de Francia en 1575, pero entonces el autor no podría ser La Boétie que murió en 1563. Advierte Armaingaud que ningún comentador ni ningún crítico señalan que varios acontecimientos señalados en el Discurso, no habían ocurrido en la fecha de la muerte de La Boetie. Entre otros pasajes, Armaingaud destaca la caracterización del tirano como afeminado, inepto para las funciones que debe cumplir, todas características raras en un tirano imaginado por el común de la gente pero que, casualmente, coincide con Enrique III quien gustaba de travestirse y disfrazado de cortesana concurría a las fiestas (Edwards, 2011, p. 86) acompañado por los mignons, jóvenes estrafalarios, profusamente enjoyados y travestidos como el mismo monarca pero que no engañaban a nadie, afirman los biógrafos críticos del último Valois.

Pero ¡Oh buen Dios! ¿qué es esto? ¿cómo diremos que se llama? ¿de qué enfermedad se trata? ¿de qué vicio? ¿no es vergonzoso que un número infinito de hombres no sólo obedecer sino humillarse: no sólo ser gobernados sino tiranizados, despojados de bienes, de padres, de mujeres, de hijos y de la vida misma? Padecer rapiñas, el latrocinio, las crueldades, no de un ejército sino de una horda de bárbaros contra los que cada uno debería defender su vida a costa de su sangre, sino de uno solo [...] muchas veces es el más cobarde y el más afeminado de la nación, no acostumbrado a la pólvora de las batallas sino apenas a la arena de los torneos, incapaz no solo de dirigir a los hombres sino también de satisfacer a una mujerzuela. (La Boétie, 2010, p. 24)

Un tirano afeminado e impotente, sexualmente hablando, parece ser el retrato de lo que se sabía de Enrique III, sobre todo por la propaganda insidiosa de los calvinistas. Destaca Armaingaud que retornando de Polonia, el Valois habría contraído una enfermedad incurable en Venecia donde a la impotencia sexual agregó la infertilidad (Armaingaud, 1910, p.9). El episodio donde evita los campos de batalla se refiere a junio de 1574 cuando siendo Duque de Anjou y Rey de Polonia debe abandonar ese reinado para instalarse en Paris como Rey de Francia. Lo convocan para comandar la represión a un alzamiento rebelde en Languedoc y en la Dauphiné pero se encierra en Avignon (Armaingaud 1910, p.11).

En apoyo de su tesis, destaca Amengaud que Montaigne hace alusión a este tema de la conducta ejemplar de los monarcas que se ponen a la cabeza de las batallas y tienen actitudes de liderazgo donde la carencia de este rasgo indica una grave falta moral. En el LII Capítulo XXI titulado Contra la haraganería, en el inicio del capítulo alude a múltiples ejemplos de reyes legendarios que iban al frente de guerra, que preferían morir antes que estar a resguardo mientras otros morían por él. La publicación del Contra Uno comprende el fin del reinado de Carlos IX y los dos primeros ańos de su hermano, Enrique III. Luego de los sucesos de San Bartolomé los protestantes multi- 
plican los escritos satíricos (1574 - 1576) donde las extravagancias del Rey son motivo de múltiples críticas y hasta burlas.

Para afirmar que La Boétie no puede ser el autor del Discurso, Armaingaud sostiene que para reducir a servidumbre al pueblo, el tirano se vale de la religión. Para ello se concentra en un párrafo donde se afirma que a la obediencia y al sevilismo se suma la devoción. En apoyo a la idea de que no puede ser La Boétie el autor de estos fragmentos, cita a un estudioso de la obra del amigo de Montaigne, a M. Bonnefon, con quien coincide parcialmente, quien remarca que no podría surgir de la escritura de La Boétie una crítica tan violenta al poder monárquica y a la religión. Ni Anne Dubourg ni el propio Calvino habrían aprobado ni respaldado las ideas revolucionarias y republicanas del Contra Uno ya que eran profundamente religiosos y respetuosos de la institución monárquica (p. 127). Por otra parte, en estos mismos párrafos se cita "La Franciade de Ronsard" (La Boétie, 2010, p.53) que apareció en 1572, por lo tanto, no podría tampoco nombrarla alguien muerto en 1563.

En otro pasaje habla de "seis favoritos" (La Boétie, 2010, p. 55) que son la oreja del rey, los compañeros de placeres, cómplices de sus crueldades, copartícipes de sus rapińas. Según Armaingaud, esta denuncia no podría aplicarse más que a Enrique III y no a sus antecesores cuando la institución de los mignons no estaba devaluada al grado en que llegó a serlo con Enrique III, con la significación infamante que adquirió a partir de 1576. Antes tenía el significado de "acompañantes de rango inferior" pero estos cinco o seis favoritos, jóvenes de naturaleza asimilable a la del rey, fueron el blanco preferido de las críticas al último Valois como un tirano acompañado por jóvenes tan viciosos y licenciosos como él. Recuerda Armaignaud que luego de su partida de Polonia, Enrique de Valois se encuentra acompañado por estos seis favoritos: Villequier, Souvray, Pibrac, Bellegarde, Bellievre, el marqués D’O, el yerno de Villequier, más tres jóvenes tan licenciosos como los anteriores. Armaingaud señala que en los pasajes finales del Discurso, se mencionan a estos personajes como "addresents" en un pasaje "Ces six addressent" (p.318) y como "Mais encore, mellons que ces mignones eschappent" (p. 321). Señala que el término "adresser" en el sentido de "dresser" no se encuentra hasta fines del S. XVI, impuesto a partir de la traducción de "Las Vidas de hombres ilustres" en las Obras Morales de Plutarco, traducidas al francés en 1572. Por otra parte el uso despectivo y acusatorio del término "mignons" se identifica con el reinado de Enrique III. Descarta que la pintura que hace el autor del Contra Uno del tirano, sea la de Enrique II, Francisco II o Carlos IX ya que estos "favoritos" fueron hombres jóvenes como el rey que responden a la descripción del autor del Discurso que no podría ser La Boetie.

Para Armaingaud las principales tesis en este análisis del Discurso son las siguientes:

1) El Discurso de la Servidumbre voluntaria no es un discurso teórico sobre la tiranía sino un panfleto político

2) Nombra hechos que son posteriores a la muerte de La Boétie pero anteriores en cinco años a los que precedieron a su publicación integral en 1577.

3) El personaje principal aludido como el tirano es Enrique, duque de Anjou, luego rey de Polonia y durante los dos últimos años de este período rey de Francia.

4) Los pasajes que no pudo haber escrito La Boétile no solamente son importantes 
sino que son los centrales en vista a la provocación y al efecto que tuvieron como disparadores de una Revolución republicana en los dos siglos siguientes. Con estas tesis principales Armaingaud se opone a la historia que cuenta Montaigne sobre el autor del Discurso. La pregunta que se impone es la siguiente ¿Quién escribió las partes que La Boétie no pudo haber escrito? La composición de La Boétie, simple ejercicio de retórica de un joven de 16 años, sería un tratado aplicable a todos los tiranos y a todas las tiranías en la versión de Montaigne quien es la máxima autoridad en este tema ya que él, por registro testamentario, es el depositario del manuscrito y el responsable de su destino, nos recuerda Armaingaud (p. 42).

El 14 de agosto de 1563 La Boétie muere en brazos de Montaigne. El testamento, conservado en los Archivos departamentales de la Gironde, expresa en un párrafo citado por Armaingaud, donde La Boetie alude a la donación de "libros", no de manuscritos ni de papeles.

En lo Ensayos, en el capítulo "De la amistad", Montaigne afirma que heredó "su biblioteca y sus papeles”. Montaigne reserva durante siete años, hasta 1570, la publicación de estos escritos menos el Discurso que queda inédito siendo únicamente él el poseedor del manuscrito original, de modo que solamente a través de Montaigne queda el registro de la existencia del manuscrito.

Como autoridad reconocida sobre la obra de La Boétie, nuevamente recurre Armaingaud a M. Paul Bonnefon quien confirma los resultados negativos de la búsqueda de otro manuscrito, anterior a la publicación de 1574-1577. Este erudito desmiente la versión de Montaigne sobre la edad de La Boétie al momento de escribir el Discurso. Lo ubica entre los 22 o 23 años, siendo estudiante en la Universidad de Orleans cuando era rector Anne Dubourg. Lambert Daneau, camarada de La Boétie habría recibido la confidencia de este primer ensayo y habrían recibido junto a Anne Dubourg la primicia del Discurso. Luego ambos se hicieron fervientes calvinistas. Armaingaud rechaza esta versión del origen del Discurso ya que Anne Dubourg no podría haber aprobado un Discurso republicano y revolucionario (p.49). En este punto Armaingaud introduce otro personaje histórico en esta intrincada trama política para justificar la aparición del Discurso como un panfleto en contra de Enrique III: Michel de l'Hospital quien en 1560 fue llamado por Catalina de Medicis para organizar una política de reconciliación entre católicos y hugonotes. Esta política fracasó en 1572, cuando estalló la matanza de San Bartolomé.

En 1571 Montaigne declara que se retira a vivir recluido en su castillo para dedicarse a escribir. Según Armaingaud es difícil creer que un hombre de acción como Montaigne, a los 38 ańos, un hombre que ama la vida social, que desprecia la vida doméstica del castillo, abandone la política siendo que es un hombre exitoso en Paris. "Montaigne tiene otras razones que las que declara en 1571” (p. 53). En esta interpretación, la verdadera razón que alejó a Montaigne de la Corte es que su fineza y profundidad de observación le hicieron ver lo que estaba por venir, lo que ocurrió dos años más tarde con la Matanza de San Bartolomé: Catalina de Medicis conspira contra la política de reconciliación encomendada a L'Hospital. Su confidente, René Birague representa junto a la reina todo lo opuesto a una política de reconciliación. Los acontecimientos entonces habrían confirmado sus sospechas y el luctuoso resultado es la muerte de muchos de sus amigos. En los Ensayos aparece una mención marginal a la masacre del 24 de agosto. 
Otra de las teorías que revisa Armengaud es la de que el Discurso es una respuesta a El principe de Maquiavelo. Esta tesis la sostiene Barrére ( Joseph Barrère. "Estienne de la Boëtie contre Nicolas Machiavel. Étude sur les mobiles qui ont déterminé Estienne de la Boëtie à écrire le discours de la Servitude volontaire". Bordeaux, A. Mollat, 1908) Aquí se retoma la información de que a Maquiavelo (1469 - 1527) le publican en Roma El príncipe en 1532, cinco años después de su muerte. El joven La Boetie ya toma contacto con este escrito en 1546, en Sarlat, donde es elevado a ejemplo de gobernante Cesar Borgia, donde se valora el cinismo, la simulación y se excluye la moral de la política. Según Barrére este escrito indigna a La Boetie y se propone escribir lo que será un "antídoto para este veneno" (Armaingaud, 1910, p. 253). La Boetie pretenderá mostrar que no hay gobierno sustentable sin moral. El Discurso será el contrapunto, tema por tema, a El príncipe, según Barrére. Recordemos que mientras que El príncipe hace una descripción de los modos de dominación empleados por los poderosos, como algo natural, como parte de la esencia del ejercicio del poder, el escrito de La Boetie es un llamado a la rebelión o al menos a la resistencia. Al modo de lo que luego Kant adoptará como postura ética, la postulación de un "deber ser", ya el Discurso instiga a una toma de posición de rebeldía ante la opresión aludiendo a una motivación interna, el deseo de servir, que, como la minoría de edad que caracterizará Kant dos siglos después, es la causa de la servidumbre voluntaria. Aquí el mandato moral parece ser "no debes consentir en la servidumbre", "no debes ser cobarde", "se debe recuperar la libertad y ejercerla". No dice "sapere aude" pero podría haberlo dicho. Para Armaingaud es el propio Montaigne quien desmiente este origen del Discurso: el escrito de su amigo es un ejercicio escolar sin ninguna intención política, según afirma en los Ensayos aunque el mismo Armaingaud admite que aquí Montaigne está sembrando pistas falsas acerca del origen de este escrito. En cualquier caso, el autor es traductor de Plutarco (Chaui, 2010, p. 77) ya que son múltiples y en lugares centrales las referencias a este autor clásico tanto en el Discurso como en los Ensayos. Quizás para despistar aún más a quienes podrían pensar que Montaigne usa el nombre de su amigo muerto para difundir sus ideas acerca del poder, en los Ensayos se aleja de la posición deontológica del Discurso y parece ser solidario con la posición maquiavélica. En los Ensayos Montaigne se presenta como un conservador, cuando abre sospechas acerca de los intentos de innovar en materia de las costumbres sancionadas como leyes frente al peligro de alterar el orden vigente o al menos la necesidad de prudencia o sensatez. Dado el impacto negativo que producen estos cambios afirma:

[...] es muy dudoso que cambiando una ley aceptada tal cual, se pueda obtener un beneficio tan importante como la dificultad de eliminarla. Porque un Estado es como una construcción hecha de piezas diversas unidas por tal relación que es imposible mover una sin que todo el cuerpo lo sienta. (Montaigne, 2011, p 119)

Los que trastornan un estado son con frecuencia los primeros afectados por su ruina (Montaigne, 2011, p.120), afirma en clara contradicción con el espíritu optimista y esperanzador del Discurso. Aquí deja en claro que puede ser irresponsable alentar el espíritu de rebelión. La posición de Montaigne respecto a la autoridad de las leyes parece provenir de una posición pragmática al advertir acerca de un equilibrio entre costos y beneficios, ya que toda alteración del orden vigente podría introducir el caos y la anarquía y, por lo tanto, perjudicar antes que beneficiar la vida social, sobre todo 
para los oprimidos, cuando un nuevo orden reinstale nuevas formas de la tiranía. Montaigne reconoce que el orden social se sustenta en la necesidad de imponer un orden que "obligue" a las personas a respetar la vida y las propiedades de los demás y que el Estado es necesario dada la precaria o frágil capacidad de los humanos de convivir pacíficamente en ausencia de la fuerza de una autoridad. La imposición de la autoridad de la Ley debe tener la suficiente fuerza como para conjurar el mal mayor que es la anarquía, el desorden y la insurrección generalizada.

\section{En conclusión ...}

Para situarnos en la complejidad del momento político de Francia en las últimas décadas del Siglo XVI y ubicarnos en este rompecabezas de nombres y fechas recordemos que en 1570 Montaigne anuncia que publicará el escrito que lo atrajo a La Boétie cuando se conocieron, un escrito que le legó en su lecho de muerte su amigo y del cual él es el único poseedor testamentario. En 1571 se retira de la política y se recluye en su Castillo bajo la excusa de dedicar el resto de su vida a escribir un libro que sea el marco literario digno para poner allí los escritos que heredó de La Boétie. Declara que entre esos manuscritos no publica dos: uno se titula "Discurso sobre la servidumbre voluntaria" y el otro es una memoria sobre el "Edicto de enero de 1562". En 1572, se calcula que mueren unas 20.000 personas por causas de los enfrentamientos religiosos. Entre 1574 y 1577 aparece de manera anónima el escrito, luego será publicado bajo el pseudónimo de Etiénne de La Boétie, según Armaingaud. Los protestantes publican varios documentos donde denuncian las atrocidades de la masacre de San Bartolomé y uno de ellos, anónimo, lleva por título "Discurso de la Servidumbre voluntaria". En 1573 sube Enrique III al trono de Francia y empeora la intolerancia.

En 1574 Montaigne ve la chance de poner como rey de Francia a un joven que admiraba y reinaba en Navarra, el que luego sería Enrique IV. En 1589 asesinan a Enrique III y se inicia un período de pugnas de poder hasta que en 1594 coronan como rey a Enrique IV. A todo esto, ya retirado del mundo político, Montaigne deja transcurrir sus días en el refugio de su biblioteca en una de las torres de su castillo acompañado por reliquias traídas de los territorios de América recientemente conquistados por los españoles, por libros y por la presencia internalizada de su amigo que lo acompaña en la escritura de los Ensayos los que aparecen en una primera versión en 1580 y luego varias reediciones hasta que muere en 1592 .

Cuatro años antes de la muerte, en 1588, en Paris, conoce a una mujer que será la que acompañará su tarea de escritor durante sus últimos años y luego será, por pedido testamentario, la heredera de toda su obra escrita. Nos referimos a su hija adoptiva, Marie Le Jars de Gournay, partícipe necesaria y determinante de la publicación de los Ensayos. Podríamos decir que la presencia de Marie de Gournay, en el mundo afectivo de Montaigne, cierra un círculo o quizás mejor sería decir un triángulo en el amor entre los amigos, entre La Boétie y Montaigne, que le permite a este último terminar sus días dejando bajo la custodia de una mujer la obra de uno que admitía que era dos: el Discurso y los Ensayos. Como corresponde al vínculo de la philia, ambas obras tienen un alto grado de autonomía, incluso podríamos decir que confrontan en un diálogo polémico, donde, 
como corresponde, por momento los amigos muestran sus diferencias. Después de todo, el polemos y el agon, la guerra y el juego, otorgan potencia al pensamiento y, al parecer, ha sido una mujer quien mejor entendió la íntima naturaleza del amor de amistad que fusionó el destino de los dos filósofos. Pero esta parte es otro viaje.

\section{Bibliografía}

—Armaingaud, Arthur (1910). Montaigne panphletaire. Lénigme du Contre Un, Paris, Librairie Hachette.

—Chaui, Marilena (2010). "Amistad; rehusarse a servir", en Etienne de La Boétie, El discurso de la servidumbre voluntaria, traducción de Diego Tatián, Buenos Aires, Las Cuarenta.

— Delaruelle L. J. Barrère (1909). "Estienne de la Boëtie contre Nicolas Machiavel. Étude sur les mobiles qui ont déterminé Estienne de la Boëtie à écrire le discours de la Servitude volontaire”. En Annales du Midi: revue archéologique, historique et philologique de la France méridionale, 21, (82), pp. 237-239.

- González, A. (2011). Simone Weil y Etienne de La Boétie. Buenos Aires: Ediciones del signo.

— La Boétie, É. de (2010). El discurso de la servidumbre voluntaria, traducción de Diego Tatián. Buenos Aires: Las Cuarenta.

— La Boétie, É. de (2008). Discurso de la servidumbre voluntaria. Buenos Aires: Edición La Plata-Terramar.

— Montaigne, M. de (2011). Ensayos. Buenos Aires: Losada.

\section{Libros antiguos sobre Montaigne}

- Montaigne, su vida y su obra https://archive.org/details/montaignelhommee00bonn\&autoplay=1\&playset=1 https://www.zendalibros.com/un-tal-montaigne/\#. WlUIrL7yFuk.whatsapp [consultados el 8 de enero de 2018].

Ilustraciones de Salvador Dali a una publicación de los Ensayos, disponible en https:// www.brainpickings.org/2013/08/12/salvador-dali-illustrates-montaigne

Otras ilustraciones

https://www.google.com.ar/search?q=La+Boetie\&source=lnms\&tbm=isch\&sa=X\&ved=0ahUKEwizrOq-spPZAhWSnJAKHZIPCkIQ AUICigB\&biw=1264\&bi$\underline{h=899 \# \text { imgrc }=a Y l 5 S C q g J h Y d d M:}$

https://www.google.com.ar/search?q=La+Boetie\&source=lnms\&tbm=isch\&sa=X\&ved=0ahUKEwizrOq-spPZAhWSnJAKHZlPCkIQ AUICigB\&biw=1264\&bi$\underline{\mathrm{h}=899 \# \text { \#imgrc }=\text { s } 1 \text { iXcAuchNiqbM: }}$ 